\title{
Comparison of Intralesional Kenacort Injection Versus Surgical Intervention for Primary Chalazion
}

\author{
Narain Das, Asma Shams, Beenish Khan, Muhammad Nasir Bhatti
}

Pak J Ophthalmol 2019, Vol. 35, No. 3

\begin{abstract}
See end of article for authors affiliations
\end{abstract}

Correspondence to: Narain Das (ND) Assistant Professor SMBBMC Lyari, Karachi E-mail: narainpagarani@yahoo.com
Purpose: To compare the efficacy and safety of intralesional steroid injection versus surgical intervention (Incision and Curettage) in Primary Chalazion.

Study Design: Prospective, comparative and interventional hospital based study.

Place and Duration of Study: Shaheed Mohtarma Benazir Bhutto Medical College Lyari and Sindh Government Lyari General Hospital, Karachi from $15^{\text {th }}$ October, 2016 to $15^{\text {th }}$ April, 2017.

Material and Methods: All patients diagnosed with chalazion on clinical basis from the Outpatient department of Ophthalmology were included in the study. All patients were randomly divided into two groups with 25 patients in each group. Group 1 received intralesional $0.2 \mathrm{ml}$ triamcinolone acetonide while Group 2 received surgical intervention (Incision and Curettage).

Results: There were 50 eyes of 50 patients between the age group of 15 to 40 years and of either gender. Mean age was $25 \pm 12.2$ with male to female ratio of $2: 1$. There were $19(76 \%)$ patients who achieved complete resolution of chalazion after intra-lesional triamcinolone acetonide in group I and there were $21(84 \%)$ patients out of 25 who achieved complete resolution of chalazion after incision and curettage in group II. No ocular complication such as bleeding, elevation of intra ocular pressure, eye lid de-pigmentation or any loss of vision in either group was observed.

Conclusion: Intralesional triamcinolone acetonide injection is nearly as effective as surgical treatment (incision and curettage) in primary chalazion.

Keywords: Triamcinolone, Chalazion, Eyelid Diseases.

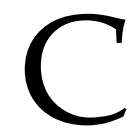
halazion is a chronic inflammatory Lipogranulomatous lesion of the eyelid ${ }^{1}$. It is the most common benign eyelid lesion accounting for $13.4 \%$ of cases ${ }^{2}$. The site of pathology is the meibomian gland, which lines the tarsus of the eyelid $^{3}$. The most common presentation is a painless lump or swelling on the upper or lower eyelid. The condition may be unilateral or bilateral, external or internal and may consist of single or multiple lesions ${ }^{2}$.

It can occur in individuals of all age groups but most commonly presents in adults with $80 \%$ lesions occurring in individuals in the age group of 11 to 30 years ${ }^{4}$. Although it can occur in any location of the eyelid, most chalazia are found on the upper eyelid. This is because of the concentrated anatomical distribution of Meibomian glands in the upper eyelid ${ }^{5}$. An inflamed chalazion can be visualized through the tarsal conjunctiva upon eversion of the eyelid. The lesion may take up the appearance of a whitish granuloma with potential to rupture $^{5}$. The most common symptoms include swelling, redness and irritation. Swollen eyelids with a hard nodule may 
also occur ${ }^{3}$. Larger lesions have a tendency to induce mechanical ptosis and cause blurred vision due to astigmatism by pressing the cornea $^{6}$. Rarely, conjunctivitis and cellulitis may also occur ${ }^{5}$.

On histology, a chalazion is composed of various inflammatory cells such as histiocytes, mononuclear lymphocytes, plasma cells, polymorphonuclear cells and eosionphils 7,8 . Chalazia can also occur with other eye conditions and can have inflammatory and viral causes. Inflammatory causes include seborrheic dermatitis, acne rosacea and chronic blepharitis. Viral conjunctivitis most commonly constitutes viral causes $^{2}$. Biopsy and microbiological analysis are needed to rule out neoplasms especially in the elderly and in recurrent chalazion ${ }^{9}$. Neoplasms which may mimic chalazia include sebaceous gland carcinoma, basal cell carcinoma, squamous cell carcinoma or merkel cell carcinoma ${ }^{2}$.

A chalazion can be treated by medical treatment as well as surgical interventions. The conservative treatment involves warm compresses for 10 minutes four times daily, eyelid massage, lid scrubs and mild topical steroids. Warm compresses help to open the glands, to break and express the nodules. Antibiotics are only indicated in conditions where the chalazion is associated with severe blepharitis or blepharitis associated with rosacea. Tetracycline is used commonly. Alternative antibiotics are azithromycin and erythromycin. Interventions include intralesional steroid injection (ILSI) triamcinolone acetonide and incision and curettage ${ }^{2}$. Injection of 0.05 to $0.3 \mathrm{ml}$ of the steroid is given in the palpebral side using the insulin syringe ${ }^{3}$.

Conservative management by warm compresses and antibiotics is effective in up to $80 \%$ of cases while ILSI is found to be effective in $93 \%$ of cases $7,10,11$. According to the literature, steroid injection is an effective management for young patients while incision and drainage is recommended for patients with multiple chalazia. Combined treatment is recommended for patients with large, recurrent and multiple chalazia ${ }^{12}$. For the past several years, a lot of research has been conducted to compare the effectiveness of ILSI triamcinolone acetonide and surgical intervention ${ }^{13}$. The literature reveals a mixed opinion and no definite conclusion has been drawn yet. Secondly, very few studies have been conducted in Pakistan to compare the effectiveness of steroid injection and surgical management.

The primary goal of our study was to compare the treatment outcomes and success of $0.2 \mathrm{ml}$ Triamcinolone injection and surgical intervention.

\section{MATERIAL AND METHODS}

The study was conducted at Shaheed Mohtarma Benazir Bhutto Medical College Lyari and Sindh Government Lyari General Hospital, Karachi for duration of six months from $15^{\text {th }}$ October, 2016 to $15^{\text {th }}$ April, 2017.

Fifty eyes of 50 patients between the age group of 15 to 40 years diagnosed with primary chalazion on clinical basis of either gender were included in the study from the outpatient department of Ophthalmology. Patients were selected after taking ethical approval and informed consent. Patients having acute infections and recurrent chalazion were excluded from the study. All patients were randomly divided into two groups with 25 patients in each group. Group 1 received intralesional $0.2 \mathrm{ml}(40 \mathrm{mg} /$ $\mathrm{ml}$ ) triamcinolone acetonide while Group 2 received surgical intervention (Incision and Curettage).

Patients were briefed about the procedure, its benefits and complications. Informed and written consent was taken from all the patients and also advised for co-operation during the procedure. Slit lamp examination was done before the procedure. Before starting the procedure in both the groups, topical anesthesia (Proparacaine $0.5 \%$ ) eye drops were instilled two to three times in the affected eyes. After taking all aseptic measures, in group I eyelid was everted and $0.2 \mathrm{ml}$ ( $8 \mathrm{mg}$ of $40 \mathrm{mg} / \mathrm{ml}$ ) of triamcinolone acetonide (injection kenacort) was injected trans-conjunctively in the center of the lesion by using 26.5 gauge needles. In some patients when it was not possible to evert the lid due to large swelling the same was injected transcutaneously. Patching was done after putting betamethasone neomycin (Betnesol$\mathrm{N})$ eye ointment for one to two hours. In group 2 lignocaine $2 \%$ with adrenaline one to two $\mathrm{ml}$ was injected subcutaneously in the eyelid over the site of the chalazion. Chalazion clamp was applied over the chalazion site and eyelid was everted, then a small vertical incision was given with surgical blade no. 11 . After that curettage was done with chalazion currette. Pressure was applied for five minutes to stop bleeding after removing the clamp. Patching was done for six hours after putting Betnesol-N eye ointment.

Post operatively, tablet Augmentin 625 mg (500 $\mathrm{mg}$ amoxicillin and $125 \mathrm{mg}$ clavulanic acid, Glaxo Smith Kline, UK) was given 3 times a day, Tablet 
Denzen DS (Serratiopertidase $10 \mathrm{mg}$, Helix Pharma) was given 3 times a day, Tablet Ibuprofen $400 \mathrm{mg}$ (Brufen 400 mg, Mylan Products Limited) 3 times a day, Moxigan eye drops 4 times a day (Moxifloxacin Hydrochloride, Barret Hodgson) and Betnesol-N eye ointment (Betamethasone and Neomycin, Pharmaceutical AB) were advised for one week.

The treatment outcomes were observed and data was collected. Data analysis was done by using SPSS version 20. Descriptive statistics was done and data was presented in the form of tables.

\section{RESULTS}

Out of 50 patients, majority consisted of males 32 $(64 \%)$ and the rest were females $18(36 \%)$. The average age at the time of presentation was $25 \pm 12.2$ years. Half of the patients underwent surgical treatment $(50 \%)$ while the other half were treated with $0.2 \mathrm{ml}$ triamcinolone injection (Table 1). The treatment outcomes of both groups were compared. Patients treated with surgical intervention had a better treatment outcome with $84 \%$ achieving complete recovery compared to $76 \%$ of patients achieving complete resolution when treated with $0.2 \mathrm{ml}$ triamcinolone (Table 2).

Table 1: General features and distribution of patients.

\begin{tabular}{|llc|}
\hline Variables $(\mathbf{n}=\mathbf{5 0 )}$ & $\begin{array}{c}\text { Mean } \pm \text { SD/ } \\
\mathbf{n}(\mathbf{\%})\end{array}$ \\
\hline Age & Male & $25 \pm 12.2$ \\
Gender & Female & $32(64 \%)$ \\
\multirow{2}{*}{ Treatment } & Group 1 & $18(36 \%)$ \\
& Group 2 & $25(50 \%)$ \\
\hline
\end{tabular}

Table 2: Outcomes of $0.2 \mathrm{ml}$ triamcinolone and surgical intervention.

\begin{tabular}{|l|l|l|l|}
\hline \multirow{2}{*}{ Variable (n=50) } & \multicolumn{2}{|l|}{ Complete Resolution } & \multirow{2}{*}{ P-Value } \\
\cline { 2 - 3 } & Yes & No & \\
\hline Group 1 & $19(76 \%)$ & $6(24 \%)$ & \multirow{2}{*}{0.480} \\
\hline Group 2 & $21(84 \%)$ & $4(16 \%)$ & \\
\hline
\end{tabular}

A total of 10 patients (20\%) failed to achieve resolution. Out of these, six were treated with ILSI and four were treated with surgical intervention.
Therefore, ILSI had a slightly greater risk of failure in our study (Table 2).

\section{DISCUSSION}

Leinfelder first proposed the treatment of chalazion by ILSI in $1964^{14}$. Since then, many studies have been conducted and have demonstrated surgery and ILSI to be equally effective $e^{4,15}$.

ILSI has proved to be an effective and safe treatment for chalazia due to the fact that it is rarely associated with serious complications. However, skin depigmentation remains a common side effect in pigmented patients. ${ }^{16}$. Ho et al stated that 2 out of 56 patient developed skin depigmentation in their study. However, in the Goawella study none of the patients out of 56 developed this complication 5 .

Other rare side effects reported in literature include yellow deposits at the site of injection ${ }^{12}$, microembolism, rise in intraocular pressure ${ }^{17}$, and formation of pyogenic granuloma ${ }^{7}$. The findings of the above studies are contradictory to our study in which no side effects of the treatment modalities were observed.

Although extremely effective, ILSI is painful compared to injection of Triamcinolone into the subcutaneous tissue ${ }^{14}$. The later causes less pain and does not require local anaesthetic. Therefore, it can be considered as an alternative first line treatment ${ }^{14}$.

Surgical treatment of chalazion is a minor surgical procedure used to treat complicated and recurrent lesions ${ }^{3}$. Post-surgical cold compresses, maintenance of eyelid hygiene and avoidance of contact lenses are essential measures to prevent infection ${ }^{18}$.

Several studies have been conducted to compare the effectiveness of both these treatments. According to a study from 2014, two ILSIs were sufficient to produce complete resolution of multiple and recurrent chalazia ${ }^{19}$. Similarly, according to Ben Simon et al most cases resolved with an average of one to two ILSIs. Resolution was defined as a decrease in size of $80 \%$ or more with no recurrence ${ }^{20}$.

CF Chung et al demonstrated a statistically significant success rate of patients treated with conservative management $(58.3 \%)$ compared to those treated with ILSI $(93.8 \%)^{14}$. TL Jackson et al concluded that surgical treatment and ILSI both are equally effective in eradicating three quarters of chalazia compared to one third treated by conservative management ${ }^{21}$. 
In the light of the above literature, it can be concluded that both ILSI and surgical treatment are equally effective. The findings of the above studies are consistent with our results in which we also observed the near equal effectivity of the injection and surgical management.

However, Biuk $\mathrm{D}$ et al states a significant difference in pain sensation experienced between the two groups. Surgical treatment resulted in higher pain scores with a median score of $6^{5}$. In contrast, patients who received ILSI did not experience any pain (pain score $=0$ ) thus producing higher rates of patient satisfaction.

Furthermore, patients treated by ILSI needed less OPD visits, did not require antibiotics or analgesics or compressive occlusion of the eye ${ }^{5}$. Therefore, ILSI is the treatment of choice in children and when the chalazion is in close proximity to the lacrimal drainage system to avoid surgical damage. Surgical treatment is preferred in cases of infected chalazion, patients not responding to ILSI and patients with suspected adenocarcinomatous lesions in which histopathology is needed for confirmation of diagnosis 5 .

It was also seen that the response to treatment correlated with the size of the lesion as demonstrated by a local study conducted by Tahir MZ et al ${ }^{15}$. The authors found that the success rate of the treatment was greater in patients presenting with lesions ranging between $2-6 \mathrm{~mm}(100 \%)$ compared to patients who had lesions sized between 6-9 mm (97\% $)^{15}$. Similarly, another study from 2017 highlighted that patients with lesions less than $5 \mathrm{~mm}$ responded well to treatment ${ }^{3}$. Furthermore, Lee J et al showed that there was no significant difference between the treatment outcomes for adult and pediatric patients undergoing treatment with ILSI. ${ }^{17}$.

\section{CONCLUSION}

Intralesional triamcinolone acetonide injection is nearly as effective as incision and curettage in primary chalazion. It means it is a good alternative first line treatment in cases where diagnosis is straight forward.

\section{REFERENCES}

1. Arbabi EM, Kelly RJ, Carrim ZI. Chalazion. BMJ. 10; 341: c4044.

2. El Sayed MA, Kahtani S. Chalazion management: evidence and questions. Ophthalmic pearls. 2015; 9: 3739.
3. Janicijevic-Petrovic MA, Jancic S, Janicijevic K, Popovic A. Treatment of Multiple Chalazions with Intralesional Kenalog-40 Injections in Juvenile Patient: A Case Report. Maced J Med Sci. 2013 Dec. 15; 6 (4): 42124.

4. Gonagi S, Bhaskar A, Gonsalves S. Role of intralesional triamcinolone injection in management of chalazia. IOSR JDMS. 2017; 16 (10): 25-26.

5. Biuk D, Matic S, Barac J, Vukoric MJ, Biuk E, Matic M. Chalazion Treatment. Coll. Antropol. 2013; 37: 247250D.

6. Cosar CB, Rapuanob CJ, Cohen EJ, Laibson PR. Tarsorrhaphy: clinical experience from a cornea practice. Cornea, 2001; 20 (8): 787-91.

7. Parveen S, Babar ZD, Ishaq M, Islam Q. Comparison of subcutaneous extralesional and intralesional triamcinolone injection for the treatment of chalazion. Pak Armed Forces Med J. 2015; 65 (4): 502-5.

8. Yanoff M, Fine BS. Ocular pathology. 5th ed. 2002; 173174.

9. Costea, CF. Petraru, D, Dumitrescu G, Sava A. Sebaceouscarcinoma of the eyelid: anatomoclinical data. Rom J Morphol Embryol. 2013; 54 (3): 665-668.

10. Goawalla A, Lee V. A prospective randomized treatmentstudy comparing three treatment options for chalazia: triamcinoloneacetonide injections, incision and curettage and treatment with hot compresses. Clin Exp Ophthalmol. 2007 Nov; 35 (8): 706-12.

11. Ben Simon GJ, Rosen N, Rosner M, Spierer A. Intralesional triamcinolone acetonide injection versus incision and curettage for primary chalazia: a prospective, randomized Study. Am J Ophthalmol. 2011; 151: 714-718.

12. Mustafa TA, Oriafage IH. Three methods of treatment of chalazia in children. Saudi Med J. 2001; 22 (11): 96872 .

13. Aycinena AR, Achiron A, Paul M, Burgansky-Eliash Z. Incision and curettage versus steroid injection for the treatment of chalazia: A meta-analysis. Ophthalmic Plast Surg. 2016; 32 (3): 220-224.

14. Chung CF, Lai JSM, Li PSH. Subcutaneous extralesional triamcinolone acetonide injection versus conservative management in the treatment of chalazion. Hong Kong Med J. 2006; 12: 278-81.

15. Tahir MZ, Rehman M, Ahmad I, Aqbal A, Hussain I. Effectiveness of intralesional triamcinolone acetonide in the treatment of chalazion. Pak J Ophthalmol. 2015; 31: 9-14.

16. Ahmad S, Baig MA, Khan MA, Khan IU, Janjua TA. Intralesional corticosteroid injection $\mathrm{Vs}$ surgical treatment of chalazia in pigmented patients. J Coll Physicians Surg Pak. 2006; 16 (1): 42-44.

17. Lee J, Yau G, Wong M, Yuen C. Comparison of intralesional triamcinolone acetonide injection for primary chalazion in children and adults. The Scientific Journal 2014: 1-4.

18. Maurer K. Chalazion treatment [internet]. 2015; 1-3. 
www.med.umich.edu/1libr/Ophthalmology/ comprehensive/ChalazionTreatment.pdf

19. Wong MY, Yau GS, Lee JW, Yuen CY. Intralesional triamcinolone acetonide injection for the treatment of primary chalazions. Int Ophthalmol. 2014; 34 (5): 10491053.

20. Ben Simon GJ, Huang L, Nakra T, Schwarcz RM, McCann JD, Goldberg RA. Intralesional triamcinolone

\section{Author's Affiliation}

Dr. Narain Das (ND)

MBBS, FCPS (Ophthal)

Assistant Professor

SMBBMC Lyari, Karachi

Dr. Asma Shams (AS)

MBBS, FCPS (Ophthal)

Senior Registrar

SMBBMC Lyari, Karachi

Dr. Beenish Khan (BK)

MBBS, FCPS, FRCS (Ophthal)

Assistant Professor

United Medical \& Dental College, Karachi acetonide injection for primary and recurrent chalazia: is it really effective? Ophthalmology, 2005; 112 (5): $913-$ 7.

21. Jackson TL, Beun L. A prospective study of cost, patient satisfaction and outcome of treatment of chalazion by medical and nursing staff. $\mathrm{Br} \mathrm{J}$ Ophthalmol. 2000; 84: 782-785.

Dr. Muhammad Nasir Bhatti (MNB)

MBBS, FCPS (Ophthal)

Professor, SMBBMC Lyari, Karachi

\section{Author's Contribution}

Dr. Narain Das

Data collection, Performed all surgeries.

Dr. Asma Shams

Data Collection and Statistical Analysis.

Dr. Beenish Khan

Manuscript Writing and Language Correction.

Dr. Muhammad Nasir Bhatti

Critical review. 